\title{
Broadening Participation of Female Students in STEM: Significant Outcomes in Less Than One Year
}

\author{
Ms. Donna Milgram, Natl Inst for Women in Trades, Technology \& Science (IWITTS)
}

Donna Milgram is the Executive Director of the Institute for Women in Trades, Technology, and Science (IWITTS) and has been Principal Investigator on 5 National Science Foundation (NSF) grants - including the CalWomenTech Project, which was highlighted by the NSF for demonstrating significant achievement and program effectiveness and chosen as one of three model projects in the U.S. by the American Association of University Women (AAUW). A nationally recognized expert on closing the gender gap for women and girls in STEM education, Ms. Milgram has testified before the U.S. Congress on women in STEM and personally conducted hundreds of WomenTech Educators Trainings in 46 states and Canada. She has presented papers included in conference proceedings at national conferences such as the American Society for Engineering Education (ASEE) and Women in Engineering Programs and Advocates Network (WEPAN). In 2013, Ms. Milgram received a reader's choice award recipient for the cover article "How to Recruit Women \& Girls to the STEM Classroom" published by International Technology and Engineering Educators Association (ITEEA) in Technology and Engineering Teacher magazine. Recent presentation highlights include: U.S. Department of Education, Moving STEM Forward in the Career, Technical and Adult Symposium; Massachusetts Institute of Technology (MIT), Challenging Technical Privilege Symposium Panel; and, Engineering for Kids Conference (Keynote Presenter). 


\title{
Broadening Participation of Female Students in STEM: Significant Outcomes in Less Than One Year
}

\begin{abstract}
The WomenTech Educators (WTE) Online Training has cracked the code to broadening participation of female students in STEM in as little as a semester. Six of seven colleges participating in the Spring 2015 WTE Online Training reported successful outcomes in only eight months: Five of seven colleges started enrolling an average of 4.8 more female students in their targeted STEM courses and six of seven colleges increased female retention from an average baseline of 58 percent to 100 percent. The WTE Online Training was developed and introduced in 2012 during the NSF-funded CalWomenTech Scale Up (CWTSU) Project (NSF \#1102996; June 2011-May 2016) and further disseminated during the National Online WomenTech (NOW) Project (NSF \#1400531; August 2014-July 2017). It is the WTE Online Training's targeted, data-driven approach that helps institutions achieve successful outcomes in a short time period.
\end{abstract}

\section{Introduction}

The WomenTech Educators (WTE) Online Training has cracked the code to broadening participation of female students in STEM in as little as a semester with the improvements made as part of the National Science Foundation (NSF) funded National Online WomenTech (NOW) Project (NSF \#1400531; August 2014-July 2017). The larger goal of NOW Project is to increase the enrollment and retention of women (and retention of men) in community college STEM courses in which they are underrepresented. The Project is working towards this outcome by providing the national community college network with evidence-based practices in outreach, teaching skills, and learning via online professional development, and the WTE Online Training System is now resulting in successful outcomes. Six of seven colleges participating in the Spring 2015 WTE Online Training reported successful outcomes in only eight months: Five of seven colleges started enrolling an average of 4.8 more female students in their targeted STEM courses and six of seven colleges increased female retention from an average baseline of 58 percent to 100 percent [1].

The WTE Online Training was developed and introduced in 2012 during the NSF-funded CalWomenTech Scale

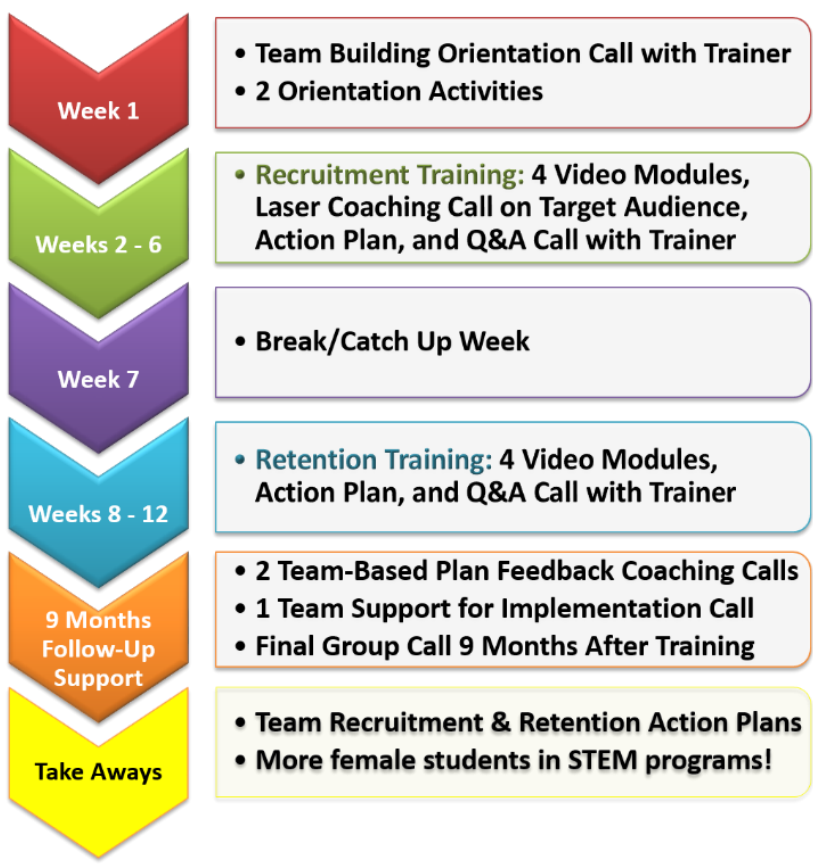

Figure 1. WomenTech Educators Online Training 
Up (CWTSU) Project (NSF \#1102996; June 2011-May 2016) and further improved and disseminated during the NOW Project. It is the WTE Online Training's targeted, data-driven approach that helps institutions achieve successful outcomes in a short time period. The WTE Online Training curriculum teaches STEM educators to work in high-functioning teams to focus on specific audiences of prospective female students for targeted recruitment instead of relying on the traditional broad brush approach of generic STEM career awareness. The team-based, 12week WTE Online Training combines asynchronous video modules and assignments with live interaction and feedback from the trainer in Team Coaching and Live Question \& Answer Calls (see Figure 1). The WTE Online Training System also includes nine months of team-based Follow-Up Support for plan development and implementation that culminates in a Group Presentation Call where teams present their outcomes.

Participants in this NSF Project's Online Training are now able to see significant increases in female enrollment and retention in targeted STEM courses after as little as one semester due to pedagogy, coaching, and Women in STEM Recruitment and Retention Plan template improvements, as well as, an improved applicant pool with higher-quality Leadership Teams.

\section{Successful outcomes from WTE Online Training participants}

Six of seven colleges participating in the Spring 2015 WTE Online Training reported successful outcomes in only eight months: Five of seven colleges started enrolling an average of 4.8 more female students in their targeted STEM courses and six of seven colleges increased female retention from an average baseline of 58 percent to 100 percent.

Details on implementation outcomes from three of the six successful teams:

- Mount Wachusett Community College (MWCC) - went from 1 female student in its introductory manufacturing class to nine females out of 13 students the next semester. Plus, 100 percent of both female and male students were retained the next semester! MWCC team's Key Leader and Dean of Workforce Development, told the story behind how his team accomplished these results with the support of the WTE Online Training System in a case study the Project's external evaluator developed. He shared that one of the most valuable parts of the WTE Online Training was building a high-functioning team and working with that team to develop and implement their plan [2]: "The most valuable aspect [of the WTE Online Training] was building our team! Getting a group of people focused and thinking about recruitment and retention was good! The training was very eye-opening; we had a vehicle to focus our efforts."

- The General Engineering Technology program at this Southeastern community college went from only two female students to 12 women in program courses in eight months. This program also went from an average baseline of 50 percent to 100 percent female retention the next semester in its targeted introductory course. During the Group Presentation Call held eight months after the WTE Online Training, this team's Key Leader shared that one of their most effective recruitment strategies was partnering with local industry to enroll women already working in the field interested in continuing their education-five of 12 female students were recruited this way. 
- A Midwestern community college saw female enrollment in their targeted introductory computer programming courses go from zero women to four female students the next semester - now 27 percent female. All four female students were also retained. This team held a "We Are IT Day" attended by around two hundred female high school students and the team's Key Leader - a female instructor with industry experience-was the keynote speaker. The team also implemented a series of retention strategies including holding additional open lab time twice a week, teaching students in targeted courses time management skills, making a full set of videos with course content available as a supplementary resource for students, and inviting a Learning Center representative to present to students on available resources.

All the teams that were successful followed the WTE Online Training System and incorporated trainer feedback into their plans. The two teams that did not see increases in female enrollment within the eight months shared the reasons why during a Group Presentation Call facilitated by the instructor as the final call of the Follow-Up Support on Implementation:

1) One team shared they chose to focus on long-term recruitment only and were currently raising career awareness in middle schools and high schools.

2) The other team's college was in the middle of re-structuring and leadership changes.

In Fall 2015, a three-day Bootcamp version of the WTE Online Training that still includes the Follow-Up Support was piloted to accommodate teams unable to commit to the full 12-week format. Six months after pilot Bootcamps, 90 percent of survey respondents have reported using a strategy they learned from the training in their work and 69 percent have reported seeing a "success" such as increased female enrollment. Three of five Bootcamp teams have also reported that they started enrolling an average of 8.5 more female students in their targeted STEM courses in less than a year [1].

The NOW Project has provided WTE Online Training to 17 teams of six to ten community college STEM educators as of Fall 2016. Colleges from NOW's first two WTE Online Trainings are already seeing early successful outcomes after NOW improved the OT by enhancing the team-building and plan development components:

1) A Southeastern community college has gone from one female student in an introductory Emerging Technologies course to 15 females out of 17 students the next semester.

2) Another Southeastern community college's Aviation Maintenance program went from 8 percent female at baseline to 15 percent and retained all female students through the following drop/add period.

3) A Northeastern community college shared that they achieved the most female students ever enrolled at one time by enrolling three female students in Machine Tool and CAD Manufacturing. 


\section{Training improvements leading to these successful outcomes}

The NOW Project Principal Investigator (PI) attributes the successful outcomes WTE Online Training teams are reporting to the series of improvements made to the WTE Online Training as part of this Project - such as enhancements to pedagogy, coaching, Recruitment and Retention Plan templates, and the application process including a Leadership Team Webinar. The Project is now seeing higher quality teams apply and is setting them up for greater success with an orientation before the training, team-building activities, team coaching, and improved plan templates. The training module content originally developed for the CWTSU Project has not changed.

One of the most significant improvements to the WTE Online Training has been incorporation of team-building activities via a required Team Development Checklist and a Team Orientation Call-half of which is devoted to how the group will function as a team in the training. For example, what strengths each member will contribute; how teams will resolve conflict; and the nuts and bolts of critical logistics such as who will submit assignments, who will collect enrollment and completion data for targeted STEM courses, and when and where (in-person or online) teams will meet each week.

Schools were asked about participating as a team during the first Q\&A call in the Online Training and in the post-training evaluation:

- "The most valuable aspect [of the WTE Online Training] was building our team! Getting a group of people focused and thinking about recruitment and retention was good! The training was very eye-opening; we had a vehicle to focus our efforts." Team Leader and Dean, Workforce Development, Northeast Community College

- "We have a fabulous team. So many people have different varied areas of expertise. We meet Wednesday mornings and everybody is energized and works hard." Instructor, Surveying \& Mapping Technologies, Southeast Community College

- 'It's been good the times we've all been together because I think we're learning a lot from each other and bouncing ideas off each other." Team Leader and Instructor, Machine Tool and Computer-Aided Manufacturing, Northeast Community College

- Meeting weekly with my team was really beneficial, I'm glad the organizers encouraged that. Anonymous, WTE Online Training Evaluation Survey

The PI is now able to work with teams right from the start of the WTE Online Training-Team Orientation Calls and Coaching Calls happen in the first two weeks - and this has allowed her to steer teams to the easiest and most effective path to broadening participation. She gives teams a strong message not to try and complete every recruitment strategy out there, but to instead focus on very targeted strategies to a specific target audience of prospective female students. This approach keeps teams from feeling overwhelmed and sets them up for success. Targeted strategies are not only more manageable for busy educators, but also more effective. 
The PI/Instructor is now receiving abundant positive feedback from teams during coaching calls:

- "Every [WTE Online Training] module is jam packed with good stuff. So it's really eye opening to me and it's giving us ideas that we have never thought about...I didn't have any ide that it could be so vast and so many different tools that you can use... We're pairing this with our grant which has already started and so we're in the planning stage of things and this is just wonderful for us. So it's just wonderful; this whole package [training] is a wonderful tool for us. " Instructor, Business, Northeast Community College

- "I know what we're going to end up with from our effort if we all stick with it is something more than hoping it will get better and a desire for it to get better. We'll have tools and a Plan that had been successful for others that, if we go through this, we should see some results that would be worthwhile." Department Chair and Instructor, Digital and Engineering Technologies, Southeast Community College

- "We were really happy that we hit our enrollment target even though our environment here at the college was markedly more challenging in some way than when we originally signed up." Team Leader/Division Dean, Science and Engineering, Northwest Community College

- "That's twice as many [female students] as we had so we did see some success. One of the things that we did was to completely revise all of our recruitment materials to include females in the pictures and in the presentations that we give." Instructor, Automotive Technology, Southeast Community College

\section{Conclusion}

This team-based online course and the accompanying Long-Term Follow-Up Support is continually being enhanced, any improvements tested for effectiveness, and the results disseminated. Online professional development such as the WTE Online Training is one of the best ways to reach community college educators with limited time and funding for professional development. The NOW Project requires colleges that apply for WTE Online Training to participate in Leadership Teams to ensure that all the key stakeholders are represented and invested in the college's Women in STEM Recruitment and Retention Plans while improving the infrastructure of community colleges to broaden participation. The WTE Online Training is successful in creating changes in the enrollment of female and retention of female (and male) students in STEM because it incorporates the research-based elements needed to encourage implementation, and requires teams to develop prescriptive action plans. The plan templates include required key elements that set teams up to be successful. NOW is based on extensive research and is already adding to the knowledgebase on effective methods for increasing STEM faculty's implementation of evidence-based teaching practices.

\section{References}


[1] D. Milgram, "CalWomenTech Scale Up Project Outcomes Report," National Science Foundation, Arlington, 2016.

[2] V. Coulon, "A Tale of Two Educators: A Case Study of Two CalWomenTech Scale-up Project Training Participants," Education Development Center, Waltham, 2016. 